\title{
Layanan Pembuatan IMB Berbasis Implementasi Kebijakan Dan Budaya Organisasi
}

\author{
Titi Darmi* \\ Administrasi Publik FISIP \\ Universitas Muhammadiyah Bengkulu, Indonesia
}

Diterima Februari 2018; Disetujui April 2018; Dipublikasikan Juni 2018

\begin{abstract}
Abstrak
Penelitian ini dilaksanakan di BPPTPM Kota Bengkulu, menurut beberapa survei bahwa layanan publik di Pemkot Bengkulu di bidang layanan administrasi berbentuk dokumen yaitu IMB berada diposisi integritas yang rendah. Diduga penyebabnya karena implementasi kebijakan dan nilai-nilai budaya organisasi belum berjalan sesuai dengan yang diharapkan. Tujuan penelitian ini untuk mengetahui sejauh mana dan seberapa besar pengaruh implementasi kebijakan dan budaya organisasi berpengaruh terhadap layanan perizinan pembuatan IMB. Metode penelitian adalah melalui pendekatan kuantitatif, sumber primer dan sekunder melalui observasi, dokumen dan angket. Responden penelitian sebanyak 192 orang. Hasil penelitian menunjukan bahwa korelasi pelayanan perizinan pembuatan IMB sangat signifikan dipengaruhi oleh implementasi kebijakan dengan angka korelasi sebesar 0,773. Sementara budaya organisasi berkorelasi sangat positif dengan angka korelasi sebesar 0,708. Secara parsial bahwa variabel implementasi kebijakan dan budaya organisasi memberikan kontribusi pengaruh sebesar $62,2 \%$ terhadap layanan perizinan pembuatan IMB di BPPT Kota Bengkulu. Sedangkan sisanya yaitu sebesar 37,8\% disebabkan oleh faktor lain diluar variabel yang diteliti.
\end{abstract}

Kata Kunci : Implementasi Kebijakan, Budaya Organisasi, Layanan IMB

\begin{abstract}
This research is held in the city government of Bengkulu province.based on the survey that public service in Bengkulu in the service administration form document that is $I M B$ was in the posisition on the law integrity. Its causes the implementation of policies and the values of the organization culture is not running well like the expectation. The objectives of this research is to know the influence of policies and organization culture implementation inpublic service. The research get from observation, document, and questioner. The respondent of this research is 195. The result of this research showed that thereis a significant correlation in public service in 0,773 . The optimal correlation in public service is very positively influenced by organization culture with corelatin of 0,708 . In the parcial, the application of variabel in implementation and organization culture gave the effect in 62,2\% contribution to increase public service. While $37,8 \%$ as the remaining, its became from another out of factors in this research
\end{abstract}

Keywords: Implementation of policy, Organization Culture, Public servicel MB.

How to Cite : Darmi, T., (2018). Layanan Pembuatan IMB Berbasis Implementasi Kebijakan Dan Budaya Organisasi 6 (1): 1-14

$\begin{array}{lr}{ }^{*} \text { Corresponding author: } & \text { P-ISSN-2549-9165 } \\ \text { E-mail: titi.harmadi@gmail.com } & \text { e-ISSN -2580-2011 }\end{array}$ 
PENDAHULUAN

Fenomena layanan publik yang masih terasa lambat dan mahalmasih dirasakan oleh nitizen (pengguna layanan). Kekecewaan pengguna layanan, tidak dapat dipungkiri acap kali kita membaca dan dibahas serta diulas di media, sering kali juga kita membaca status di media sosial baik Facebook, Twitter ataupun Instagram tentang curhatan nitizen terkait keluhan mereka terhadap pelayanan publik.

Fenomena tersebut berbanding lurus dengan hasil survey yang dilakukan oleh beberapa lembaga, Political Economic Risk Consultancy (PERC) menempatkan Indonesia di bawah Vietnam, Filipina, Thailand, Malaysia, Taiwan, Korsel, Macau, Jepang, Hongkong dan Singapura. Dengan skor 9, 27 dari skala 0-10. Sementara itu International Finance Cooperation (IFC) 2013: Rangking Doing Business menempatkan Indonesia pada peringkat 120 dari 180 negara. Kemudian Index Global Competitiveness Report peringkat 34 dari 144 negara. Di level ASEAN Indonesia masih berada di bawah Singapura, Malaysia dan Thailand untuk Indeks Persepsi Korupsi yakni Peringkat 107 dari 175 negara (ORI, 2015). Artinya, Indonesia harus kerja lebih keras lagi agar Indonesia bisa bersaing dengan negara negara lainnya dalam rangka menghadapi globalisasi.

Untuk meningkatkan pelayanan publik, penyelenggara negara sudah memiliki instrumen kebijakan. Instrumen kebijakan ini seyogiyanya dapat memberikan dorongan

para pemangku kebijakan untuk mengeksekusi program-program terkait peningkatan kualitas pelayanan publik. Intrumen kebijakan terkait pelayanan publik, yakni, 1) UU Nomor 25 tahun 2009 tentang Pelayanan Publik; 2) Peraturan Pemerintah Nomor 97 Tahun 2012 tentang Pelaksanaan Pelayanan Publik; 3) Peraturan Presiden Nomor 76 Tahun 2013 tentang Pengelolaan Pengaduan Pelayanan Publik; 4) peraturan Presiden Nomor 97 Tahun 2014 tentang Pelayanan Terpadu Satu Pintu (PTSP); 5) Permenpan Nomor 15 Tahun 2014 tentang Pedoman Standar Layanan. Dan dipertegas dengan adanya instrumen kebijakan UU Nomor 23 Tahun 2014 tentang Pemerintah Daerah.Penyelenggara Negara sudah diberikan kewenangan luas untuk mengelola daerahnya sesuai dengan potensi dan kebutuhan masyarakat.

Provinsi Bengkulu adalah salah satu daerah masuk kategori tertinggal diurutan nomor 2 diantara provinsi yang ada di pulau Sumatera. Akan tetapi berdasarkan survei yang dilakukan Ombudsman tahun 2016, Provinsi Bengkulu memiliki Kepatuhan terhadap Pelayanan Publik sangat baik mendapat nilai 83,31 , namun, ibarat bumi dan langit hasil survei Ombudsman menunjukkan hasil yang jauh berbeda yang dimiliki oleh lbu Kota Provinsi Bengkulu (Kota Bengkulu) yang mendapat zono merah setiap tahunnya, baca tabel 1 dibawah ini. 
Tabel 1. Kepatuhan Penyelenggara Negara terhadap Pelayanan Publik

\begin{tabular}{llll}
\hline No & Tahun & $\begin{array}{l}\text { Provinsi } \\
\text { Bengkulu }\end{array}$ & $\begin{array}{l}\text { Kota } \\
\text { Bengkulu }\end{array}$ \\
\hline 1 & 2015 & 27,00 & 29,62 \\
2 & 2016 & 83,31 & 38,70 \\
\hline
\end{tabular}

Sumber : Ombudsman Rl, 2016.

Tabel di atas memberikan informasi bahwa ketertinggalan pada tahun sebelumnya dapat dicapai pada tahun yang akan datang, artinya Provinsi Bengkulu mengambil pelajaran pada tahun yang lalu untuk bekerja lebih keras agar tahun depan mendapatkan kualitas pelayanan publik yang prima. Lain halnya, dengan Kota Bengkulu, walaupun terjadi peningkatan angkah 9,08 tetapi angka tersebut masih masuk di zona merah, artinya tingkat kepatuhan penyelenggara negara dalam melaksanakan kebijakan belum sesuai harapan masyarakat dan dapat dimaknai kepuasan pengguna layanan terhadap layanan yang diberikan belum mencapai klimaks.

Salah satu produk pelayanan publik yang diberikan oleh Pemerintah Daerah (Pemda) Kota Bengkulu berupa layanan secara administratif yaitu menerbitkan dokumenpembuatan lzin Mendirikan Bangunan (IMB). Pengurusan IMB menjadi tanggung jawab BPPTPM Kota Bengkulu. Dari 99 jenis perizinan dan 25 jenis non perizinan yang menjadi tanggung jawab BPPTPM, IMB yang menjadi sorotan masyarakat karena penyelesaian dalam pembuatan lzin tidak pernah sesuai dengan SOP yang telah ditentukan. SOP pengurusan perizinan dan non perizinan di BPPTPM Kota Bengkulu seperti tabel 2 di bawah ini:

Tabel 2. SOP Pengurusan Perizinan di BPPTPM Kota Bengkulu

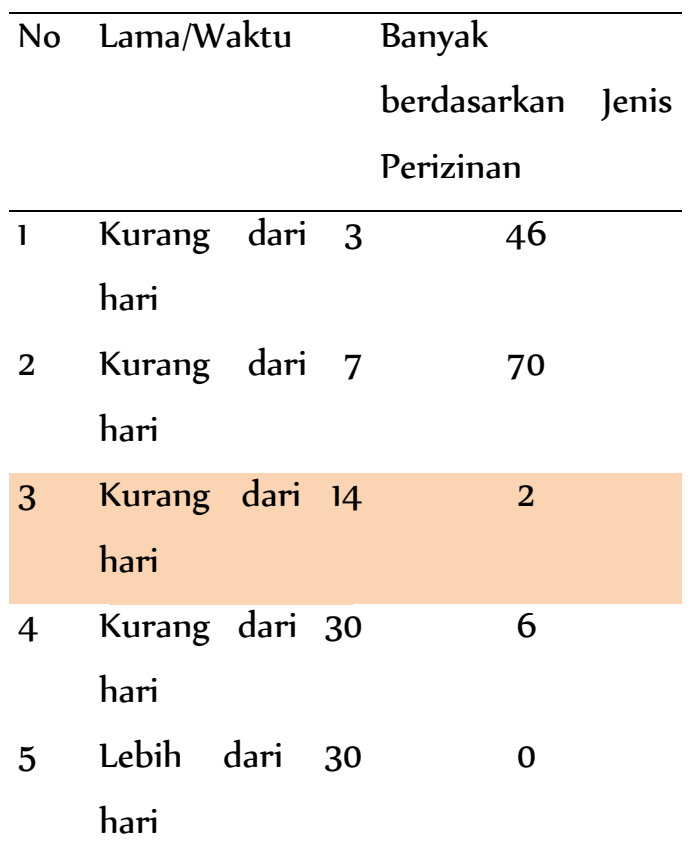

Sumber : BPPTPM Kota Bengkulu, 2016

Tabel di atas menjelaskan SOP atau rentang waktu pelaksanaan pengurusan perizinan (99 jenis) maupun non perizinan (25 jenis). IMB berada di nomor 3 , penyelesaian pelaksanaan pengurusan IMB kisaran 12 hari kerja. Pada saat penelitian awal, peneliti memberikan pernyataan kepada pengguna layanan terkait konsistensi waktu layanan pengurusan IMB. Apakah waktu penyelesaian pengurusan perizinan IMB sudah sesuai dengan SOP yang telah ditentukan? Enam dari tujuh pengguna layanan memberikan jawaban atas pertanyaan tersebut mengatakan bahwa penyelesaian pengurusan $\mathrm{IMB}$ belum perna 
selesai dalam waktu 14 hari kerja. Artinya, penerapan kebijakan belum sepenuhnya dilaksanakan oleh pelaksana pelayanan publik.

Belum cermatnya pelaksana kebijakan dalam mengimplementasikan kebijakan tersebut diduga dikarenakan aparatur negara belum melaksanakan nilai-nilai yang tertanam di kantor BPPTPM. Nilai-nilai atau kebiasaan perilaku aparatur merupakan cerminan budaya organisasi. Berdasarkan penelitian (Darmi, 2013) yang dilakukan di DPPKA Kota Bengkulu mengatakan bahwa Budaya Organisasi memiliki pengaruh positif terhadap kinerja aparatur.

Uraian di atas terdapat benang merah antara implementasi kebijakan dan budaya organisasi dengan pelaksanaan pelayanan publik.Diasumsikan implementasi kebijakan dan budaya organisasi berkontribusi terhadap kualitas pelayanan publik. Tulisan ini berupaya memberikan gambaran yang faktual tentang bagaimana penerapan kebijakan atau pelaksanaan peraturan dan budaya organisasi terhadap pelayanan pembuatan IMB dan memberi solusi kepada pemangku kebijakan di Pemerintah Kota Bengkulu agar dapat mengimplementasikan kebijakan dan budaya organisasi demi kualitas pelayanan publik di Kota Bengkulu, khususnya dalam pengurusan perizinan IMB.

Transformasi paradigma administrasi public menurut Denhardt dan Denhardt (2003) adalah suatu keniscayaan.Seiring ada perubahan sosial maka Paradigma administrasi publik lama tergeser menjadi administrasi publik terkini yakni dengan adanya konsep new public service. Indonesia sudah mengakomodasi konsep tersebut melalui terbitnya peraturan perundang-undangan, misalnya, UU Nomor 25 Tahun 2009 tentang Pelayanan Publik.uU pelayanan publik sudah memposisikan masyarakat sebagai citizens, dengan maksud pemberi layanan memberikan layanan sesuai dengan kebutuhan/keinginan masyarakat.

UU Pelayanan Publikmerupakan salah satuproduk administrasi publik. Produk tersebut menjadi ciri setiap proses dalam pengambilan keputusan yang akan teraplikasi dalam kebijakan publik. Kebijakan publik dibuat sebagai strategi untuk memberikan solusi dalam penyelesaian setiap masalah yang dihadapi publik.

Penelitian tentang implementasi kebijakan sudah banyak dilakukan oleh para peneliti baik dari luar negeri maupun dalam negeri. Kajian yang dilakukan oleh para peneliti luar negeri seperti yang tertuang dalam tulisan Edwards (1980); Bolong (2003); Grindle (1980); Grindle dan Thomas (1991); Howlett, Ramesh dan Pearl (2009); Mahalingam (2012); Parsons (1997); Torgerson (2007); Starling (1979). Kajian dalam negeri yang dilakukan oleh para peneliti seperti Kusnandar (2005); Nugroho (2014); Suwitri (2011); Suwitri dkk (2014); Purwanto dan Sulistyastuti (2012); Kamuli (2014). Tulisan para peneliti di atas memperkokoh bahwa implementasi 
kebijakan dilakukan agar tujuan suatu kebijakan dapat dicapai sehingga masalah yang dihadapi publik dapat teratasi. Para peneliti di atas menegaskan bahwa implementasi kebijakan publik adalah cara agar sebuah kebijakan dapat mencapai tujuannya, langkah yang dilakukan dengan cara langsung menerapkan dalam bentuk program atau melalui formulasi kebijakan dengan terbentuknya Perda dan kebijakan publik penjelas atau peraturan pelaksanaan.

Menurut Grindle (1980) keberhasilan implementasi kebijakan sangat tergantung pada dua unsur yakni isi kebijakan dan konteks implementasi. lsi kebijakan mencakup hal-hal: 1) kepentingan yang terpengaruh oleh kebijakan; 2) manfaat yang akan diterima oleh sasaran kebijakan; 3) seberapa besar perubahan yang diinginkan; 4) otoritas pembuat kebijakan; 5) orang yang melaksanakan kebijakan; 6) sumberdaya yang mendukung. Sedangkan, konteks implementasi, mencakup hal-hal : 1) kekuasaan, kepentingan dan strategi aktor yang terlibat; 2) ciri khas lembaga atau pempinan; 3) ketaatan dan kemampuan menerima.

Kesuksesan penerapan implementasi kebijakan tergantung bagaimana pola dan nilai-nilai serta norma yang ada dalam organisasi publik. Pola, nilai dan norma tersebut akan membentuk budaya organisasi. Budaya organisasi mampu membentuk integritas organisasi dan integritas anggota organisasi. Budaya organisasi yang memiliki integritas yang baik diyakini akan mampu memberikan kontribusi pada pencapaian suatu kebijakan publik. Kontribusi budaya organisasi diyakini dapat meningkatkan kinerja organisasi. Keyakinan tersebut telah diulas oleh para peneliti diantaranya Robin (2014); Keban (2008); Darmi (2013); Bourgeonis(2008); Johannes (2006); Sembiring (2012).

Implementasi kebijakan publik yang menarik untuk dicermati adalah UU Nomor 25 Tahun 2009 tentang Pelayanan Publik. Untuk mendapatkan pelayanan yang prima sangat ditentukan eksekusi para aktor pelaku dalam mengimplementasikan kebijakan. Pemerintahan Jokowi menjadikan indikator pelayanan publik sebagai kinerja setiap institusi baik pusat maupun daerah.Oleh karena itu kinerja pelayanan publik penting dilakukan kajian dari berbagai perspektif.

Masalah pelayanan publik sudah menjadi konsentrasi serius penelitian di berbagai negara, baik negara maju maupun negara berkembang. Penelitian yang terkait kualitas pelayanan, diantaranya baca tulisan (Deininger \& Mpuga, 2005; Bhattacharya et al. 2016; Alexandria, 2001; Duhamel et al. 2014). Kajian terkait pelayanan publik dari persepktif manajemen atau tata kelola, dimensi-dimensi, indikator serta studi kasus tentang pelayanan publik dalam rangka mencapai kualitas pelayanan publik, diantara tulisan (Santoso 2015; Juliani \& Oliveira 2016; Elston 2016; Ciobanu \& 
Androniceanu 2015; Abdullah, A. 2008; Antonakas et al. 2014).

Kualitas pelayanan publik dilihat sejauhmana respon masyarakat terhadap layanan yang diberikan. Kepuasan masyarakat akan menjadi indikator pelayanan yang prima. Para pakar memberikan indikator pelayanan publik, menurut (Tjiptono, 1999) kualitas pelayanan jasa memiliki atribut - atribut terdiri dari, ketepatan waktu pelayanan, akurasi pelayanan, kesopanan dan keramahan pemberi layanan, kemudahan dalam mendapatkan pelayanan, kenyamanan dalam mendapatkan pelayanan, ketersediaan sarana prasarana. Zeitham, et.at (1990) indikator kualitas pelayanan publik apabila ada, tangibles, reability, responsiveness, assurance, empathy. Sampara, Lembaga Administrasi Negara (LAN) RI (1998) yang tertuang dalam Kepmenpan Nomor 81 Tahun 1995 memberikan beberapa indikator dalam pelayanan publik yang baik, yang meliputi antara lain, kesederhanaan, kejelasan, keamanan, keterbukaan, efisiensi, ekonomis, keadilan ketepatan waktu, kreteria kuantitatif.

Ketercapaian kualitas pelayanan publik tergantung seberapa besar keinginan atau perhatian para pemberi layanan (aparatur sipil negara). Keinginan dan perhatian akan tercermin pada perilaku Organisasi. Perilaku organisasi akan menciptakan budaya organisasi yang menyangkut sistem makna/nilai yang dianut bersama dalam organisasi, sehingga kebiasaan dalam berperilaku anggota organisasi dapat mencapai standar dan sasaran visi misi organisasi serta dapat memberikan hasil yang baik apabila didukung oleh anggota organisasi yang dapat memahami nilai-nilai, yang ada di organisasi. Pemahaman tugas dan fungsi masing - masing oleh anggata organisasi akan mencerminkan budaya organisasi itu sendiri. Dalam konteks kajian ini, menerapkan/implimentasi kebijakan atau menerapkan peraturan-peraturan perlu adanya komitmen anggota organisasi, membiasakan melakukan dan berperilaku sesuai dengan nilai-nilai dan aturan organisasi.

Menurut Robin (2014) indikator budaya organisasi dapat dilihat dari empat faktor yaitu; 1)Karakteristik individu dan profesional anggota organisasi. Kerena modal utama budaya organisasi adalah orang yang berada di dalam organisasi dan membentuk kebiasaan anggotanya dalam melayani masyarakat sesuai tujuan organisasi; 2) Etika organisasi. Pemahaman nilai-nilai budaya yang akan membentuk kepribadian dan kepercayaan anggota organisasi terhadap pemimpin dan tim manajemen puncak dan di luar kendali organisasi. Kadang kala, organisasi secara sadar dan sengaja mengembangkan nilainilai budaya tertentu untuk mengendalikan perilaku anggota; 3) Hak-hak yang diberikan organisasi kepada pegawai. Apakah organisasi sudah memberikan hak- 
hak pegawai sesuai dengan peraturan organisasi tersebut. Hak tersebut akan memberikan motivasi kepada anggota organisasi dalam mencapai visi misi; 4) Struktur Organisasi. Melihat bagaimana struktur organisasi dapat mengeksesuksi dan memberikan arah bagi anggota organisasi melakukan pekerjaan, sehingga anggota organisasi dalam berperilaku serta memiliki kebiasaan sesuai yang dikehendaki organisasi.

Penggabungan aspek implementasi kebijakan menurut Grindle (1994) dengan indikator dalam budaya organisasi menurut Robin (2014)serta indikator kualitas pelayanan publik menurut Zeitham, et.at (1990) akan dijadikan pedoman untuk membuat pertanyaan yang akan diberikan kepada responden dan untuk menganalisis data empiris dalam penelitian ini.

Berdasarkan uraian di atas maka dibuatlah kerangka konseptual dalam penelitian ini. Konseptual ini mengasumsikan antara variabel implementasi kebijakan(XI) dan budaya organisasi (X2)akan mempengaruhi kualitas pelayanan publik (Y). Dengan asumsi tersebut maka terbentuk hepotesis yakni: Hepotesis ke 1 implementasi kebijakan (XI) berpengaruh terhadap pelayanan publik $(\mathrm{Y})$. Hepotesis ke 2 budaya organisasi (X2) berpengaruhi terhadap pelayanan publik (Y).

\section{Metode Penelitian}

Metode penelitian menggunakan pendekatan kuantitatif, sumber data melalui observasi, angket dan dokumentasi. Responden penelitian sebanyak 192 orang, yang terdiri dari 42 orang pegawai pada kantor ВРPТРM dan 150 orang pengguna layanan. Cara penentuan responden, yakni : 1) untuk aparatur sipil negara total populasi dijadikan responden; 2) responden dari pengguna layanan dilakukan dengan menggunakan teknik acciddental sampling, teknik penentuan sampel berdasarkan kebetulan, siapa saja pengguna layananyang melakukan pengurusan perizinan IMB pada saat peneliti sedang melakukan penelitian, menjadi responden dalam penelitian ini.

Kuesioner disusun dalam skala Likert sebagai formasi item-item pengukut variabel penelitian berbentuk pernyataan persetujuan dengan lima pilihan alternatif jawaban: Sangat Sesuai (SS), Sesuai (S),Kurang Sesuai (KS), Tidak Sesuai (TS), dan Sangat Tidak Sesuai (STS). Untuk pernyataan yang bersifat favorable (positif), diberlakukan skor sebagai berikut: $\mathrm{SS}=5, \mathrm{~S}=4, \mathrm{KS}=3, \mathrm{TS}=$ 2 , dan STS = 1. Sedangkan untuk yang bersifat unfavorable (negatif) diberlakukan skor sebaliknya: $\mathrm{SS}=1, \mathrm{~S}=2, \mathrm{KS}=3, \mathrm{TS}=4$, dan STS $=5$

Untuk mengetahui korelasi antar variable dependen independen, pengujian hepotesis, data dianalisis dengan menggunakan regresi lineir berganda, menggunakan rumus: 
$Y^{\prime}=a+b_{1} X_{1}+b_{2} X_{2}+e$. Dan uji hipotesa mengunakan uji $f$ dan uji $t$.

\section{Hasil dan Pembahasan}

Dari analisis regresi lineier berganda digunakan untuk mencari dan menguji pengaruh penerapan pelaksanan implementasi dan budaya organisasi $(\mathrm{XI}$ dan X2) terhadap layanan perizinan pembuatan IMB (Y) di BPPTM Kota Bengkulu, Hasil uji analisis data dengan menggunakan regersi linear berganda dapat dilihat di bawah ini.

\section{Koefisien Determinasi $\left(\mathbf{R}^{2}\right)$}

Koefisien determinasi

merupakan koefisien yang digunakan untuk mengetahui besarnya pengaruh variabel independen terhadap variabel dependen. Hasil perhitungan koefisien determinasi dapat dilihat table di bawah ini:

Tabel 1

Hasil Uji Analisis Korelasi Regresi

\begin{tabular}{|c|c|c|c|c|}
\hline Model & $\mathrm{R}$ & $\mathrm{R}$ Square & $\begin{array}{c}\text { Adjusted R } \\
\text { Square }\end{array}$ & $\begin{array}{c}\text { Std. Error of } \\
\text { the Estimate }\end{array}$ \\
\hline 1 & $.789^{\mathrm{a}}$ & .622 & .610 & .34937 \\
\hline
\end{tabular}

a. Predictors: (Constant), $(\mathrm{X} 2)$ dan (XI)

b. Dependent Variable: Pelayanan Publik (Y) (olah data, 2016)

Dari table 1 di atas, hasil data regresi lineir berganda dengan mengunakan aplikasi program SPSS (Special for Program Statistik Science) 16, menunjukkan hasil adalah Angka R sebesar 0,789 munujukkan bahwa korelasi / hubungan antara implementasi kebijakan atau penerapan segala peraturan perundang-undangan $(\mathrm{X} \mathrm{I})$ dan budaya organisasi atau kebiasaan perilaku anggota organisasi dalam melaksanakan peraturan yang ada(X2)dengan layanan pembuatan perizinan pembuatan IMB yang diterima masyarakat $(\mathrm{Y})$ adalah positif.

Koefisien Korelasi berganda yang diperoleh dari hasil analisis data menunjukkan angka $\mathrm{R}$ square atau Koefisien Determinasi adalah 0,622 (berasal dari 0,789 $x \quad 0,789$ ). Hal ini berarti $62,2 \%$ layanan perizinan pembuatan IMB di BPPTPM Kota Bengkulu dipengaruhi bagaimana para pelaku kebijakan atau pelaksana kebijakan mampumenjalankan semua SOPyang telah ditentukan. Aparatur (pemberi layanan) dapat memberikan nilai-nilai profesional dalam bekerja yang sesuai dengan nilai-nilai organisasi sehingga masyarakat merasa puas dengan layanan yang diberikan dalam pembuatan perizinan IMB di BPPTPM Kota Bengkulu. Sedangkan, sisanya $(100 \%$ $62,2 \%=37,8 \%$ ) dipengaruhi oleh faktorfaktor lain yang tidak menjadi indikator dalam penelitian ini.

Data analisis memberikan informasi bahwa implementasi kebijakan dan budaya organisasi berpengaruh signifikan terhadap layanan pembuatan IMBdi BPPTPM Kota Bengkulu. Terkonfirmasinilai koefisien regresi berkontibusi $62,2 \%$, artinya, implementasi kebijakan dan budaya organisasi berpengaruh signifikan terhadap layanan pembuatan IMB diBPPTM Kota Bengkulu. 


\section{Pengujian Hipotesis Dengan Uji F (F-Test).}

Uji F digunakan untuk mengetahui apakah variabel $\mathrm{X}_{1}$ dan $\mathrm{X}_{2}$ secara stimultan berpengaruh seginfikan terhadap $\mathrm{Y}$, derajat yang digunakan adalah 0.05 , apabila nilai $F$ hasil perhitungan lebih besar dari nilai $F$ tabel maka hipotesa diterima. Uji $\mathrm{F}$ pada penelitian ini dapat lihat dalam tabel di bawah ini.

Tabel 2

Uji Hipoteses Dengan Uji F-Test

\begin{tabular}{|c|c|c|c|c|c|c|}
\hline \multicolumn{2}{|c|}{ Model } & \begin{tabular}{|l|} 
Sum of \\
Squares
\end{tabular} & Df & $\begin{array}{l}\text { Mean } \\
\text { Square }\end{array}$ & $\mathrm{F}$ & Sig. \\
\hline \multirow{3}{*}{1} & Regression & 13.047 & 2 & 6.523 & $\begin{array}{l}53.4 \\
45\end{array}$ & $.000^{\circ}$ \\
\hline & Residual & 7.934 & 65 & .122 & & \\
\hline & Total & 20.981 & 67 & & & \\
\hline \multicolumn{7}{|c|}{$\begin{array}{l}\text { Sumber : data diolah tahun 2016. a. Dependent } \\
\text { Variable: Pelayanan Publik }(\mathrm{Y})\end{array}$} \\
\hline
\end{tabular}

Berdasarkan hasil penelitian dengan menggunakan SPSS, untuk menguji koefisien secara menyeluruh digunakan uji F. Uji F dimaksudkan untuk menguji apakah variabel-variabel independen secara bersama-sama berpengaruh signifikan terhadap variabel dependen. Dari Uji Anova atau $\mathrm{F}$ test, didapat $\mathrm{F}$ hitung adalah 53.445dengan tingkat signifikansi 0,000. Karena probabilitas $(0,000)$ jauh lebih kecil dari 0,05, maka Xı implementasi kebijakan atau peneraparan peraturan yang ada dan X2 kebiasaan perilaku anggota organisasi (Budaya organisasi) secara simultan berpengaruh signifikan terhadap layanan perizinan pembuatan IMB di Pemkot Bengkulu ( $\mathrm{Y}$ ).

Pengujian Hipotesis Dengan Uji T (T-Test).

Uji $t$ digunakan untuk mengetahui apakah variabel independen implementasi kebijakan atau penerapan perundangaundangan $(\mathrm{X})$ dan perilaku anggota organisasi yang akan membentuk budaya Organisasi (X2) secara parsial berpengaruh nyata terhadap variabel dependen layana pembuatan perizinan pembuatan IMB $(\mathrm{Y})$, derajat signifikansi yang digunakan adalah 0,05 , apabila nilai signifikan lebih kecil dari derajat kepercayaan maka hipotesis dapat diterima, seperti table di bawah ini.

Tabel 3

Uji Hipoteses Dengan Uji T-Test Coefficients ${ }^{a}$

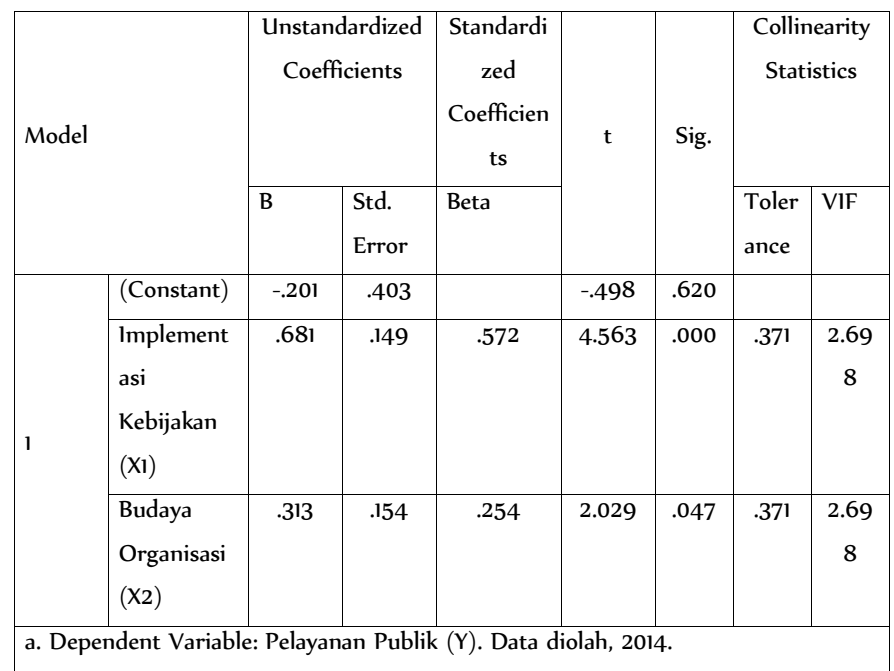

Pada tabel di atas nilai sig variabel implementasi kebijakan $(\mathrm{XI})=0.000$ artinya $<0.05$ sehingga hepotesis ke 1 diterima. Variabel independen ini secara parsial berpengaruh positif dan signifikan terhadap variabel layanan pembuatan 
perizinan $\mathrm{IMB}(\mathrm{Y})$. Makin baik penerapan suatu kebijakan (XI), maka layanan perizinan pembuatan IMB di BPPTPM Kota Bengkulu akan semakin baik (Y). Selanjutnya, pada tabel 3. di atas nilai sig variabel X2 (budaya organisasi) $=0.047$ lebih kecil dari 0.05 (< 0.05$)$, maka hipotesis ke 2 (X2) budaya organisasi di terima. Artinya, budaya organisasi berpengaruh signifikan terhadap pelayanan publik pengurusan perizinan IMB.

Berdasarkan analisis data empirik pada tabel di atas maka hipotesis ke 1 dan hipotesa ke 2 diterima, yang berarti variabel independen ini secara parsial berpengaruh positif dan signifikan terhadap variabel $\mathrm{Y}$ (pelayanan publik pengurusan perizinan $\mathrm{IMB}$ ).

Secara keseluruhan, berdasarkan perhitungan koefisien determinasi sebesar 0,622. Hal ini menunjukkan bahwa penerapan implementasi kebijakan dan budaya organisasi bersama-sama memberikan kontribusi sebesar 62,2\% terhadap peningkatan pelayanan perizinan pembuatan IMB di Pemkot Bengkulu. Sedangkan sisanya yaitu sebesar $37,8 \%$ disebabkan oleh faktor lain diluar variabel yang diteliti.

Data analisis secara empiris menunjukkan bahwa implementasi kebijakan dan budaya organisasi berpengaruh signifikan terhadap pelayanan publik pengurusan perizinan IMB di BPPTPM Kota Bengkulu. Artinya, Pelayanan publik pengurusan perizinan
IMB akan berkualitas apabila pelaksanan peraturan perundang-undang baik berupa Perda, SOP, surat edaran diterapkan secara konsistenyang didukung oleh profesionalisme yang tercermin pada sikap, perilaku anggota organisasi dalam memberikan pelayanan.

Sukses tidaknya implementasi kebijakan pelayanan perizinan pembuatan IMB dipengaruhi oleh banyak variabel atau faktor, masing-masing variabel tersebut memiliki keterkaitan satu dengan yang lainnya (Grindle, 1980). Banyak aktor dan institusi lain yang terlibat, diantaranya Dinas Tata Kota (sekarang diambil alih Dinas PU), tetangga (kiri, kanan, belakang), RT, RW, Kelurahan dan Kecamatan. Data empiris dilapangan menunjukkan terjadi kesulitan pengguna layanan IMB dalam memenuhi persyaratan pembuatan IMB.Misal, persyaratan adanya gambar kontruksi rumah.

Kontruksi rumah yang diajukan harus terlihat baik dari depan, samping ataupun belakang. Pembuatan kontruksi rumah sesuai ketentuan menjadi suatu masalah bagi masyarakat yang ingin mengajukan pengurusan IMB, karena tidak semua masyarakat mengerti dan paham cara membuat kontruksi rumah yang sesuai ketentuan Dinas Tata Kota.

Persyaratan pembuatan gambar dan kontruksi bangunan, memilki peluang terjadinya "kangkolingkong" antara pengguna layanan dan pelaku kebijakan/aparatur yang membidangi. Data 
empiris memberikan informasi bahwa proses pembuatan gambar dan kontruksi rumah merupakan persyaratan yang paling lama untuk diakomodasi oleh pihak terkait, karena banyak kesalahan yang diajukukan oleh pengguna layanan.

Selain itu, ketidaksingkronan antara instrumen kebijakan yang telah diterbitkan pemerintah (terutama PP Nomor 97 Tahun 2014 tentang PTSP) dengan keadaan yang sesungguhnya, membuat lama proses layanan tidak sesuai dengan kebijakan yang telah ditentukan. Hal ini, dipicu karena belum adanya titik temu kesepakatan untuk melayani masyarakat dengan pola satu pintu, selain itu kurang tegasnya aktor pelaksana kebijakan dalam mengeksekusi instrumen kebijakan yang telah ditetapkan pemerintah pusat.

$$
\text { Pada dasarnya implementasi }
$$

kebijakan tidak selalu mulus dalam penerapan di lapangan. Banyak faktor penghambat,selain yang telah diuraikan di atas, yang menjadi faktor pengambat adalah perilaku anggota organisasi dan budaya organisasi yang tidak sesuai nilai dan kaidah yang berimplikasi pada kinerja aparatur. Seperti, penelitian Darmi (2013) budaya organisasi berkontribusi signifikan terhadap kinerja aparatur, uji keseluruhan variabel dengan analisis lineir berganda, secara bersamaan budaya organisasi dan kinerja organisasi memberikan sumbangan yang cukup memadai dan mempengaruhi kinerja aparat dalam rangkaoptimasliasi pencapaian target PAD pada DPPKA Kota Bengkulu.

Untuk meminimalkan kesulitan masyarakat pengguna layanan $\mathrm{IMB}$, penting adanya karakteristik aparatur sebagai implementator suatu kebijakan yang ditunjukkan melalui komitmen, kejujuran, impati, senang membantu dengan rasa ikhlas kepada pengguna layanan IMB dalam menghadapi kesulitan terutama pada penyediaan persyaratan pembuatan gambar dan kontruksi rumah. Sikap-sikap tersebut di atasapabila dibiasakan dan menjadi kebiasaan para aparatur dalam melayani publik akan menjadi budaya organisasi yang secara signifikan karakteristik tersebut dapat meningkatkan kinerja pelayanan publik.

\section{Simpulan}

Dari hasil penelitian, pembahasan dan analisis, peneliti mencatat bahwa secara parsial variabel penerapan implementasi kebijakan dan budaya organisasi memberikan kontribusi pengaruh sebesar $62,2 \%$ terhadap layanan perizinan pembuatan IMB di Kota Bengkulu. Sedangkan sisanya yaitu sebesar $37,8 \%$ disebabkan oleh faktor lain diluar variabel yang diteliti. Artinya, penting komitmen implementator kebijakan dalam mengeksekusi setiap peraturan perundangan-undangan yang telah ditetapkan.

$$
\text { Dalam mengeksekusi kebijakan }
$$
penting adanya penerapan budaya organisasi oleh para pemberi layanan. Budaya 
organisasi tercermin pada sikap dan perilaku yang profesional, pemahaman nilai-nilai, pemahaman terhadap etika organisasi dan memberikan pelayanan dengan kesungguhan hati kepada pengguna yang menginginkan layanan di Kantor BPPT Kota Bengkulu.

\section{DAFTAR PUSTAKA}

Abdullah, A., and Roberston, H.V.D., 2008. Enhancing the Performance of the Public Service in a Developmental State: A Country Case Study of Nigeria. 2010, pp.1-20. Available at: unpanl.un.org/intradoc/public/unpan 03258.

Antonakas, N.P., Seimenis, l. \& Konstantopoulos, N., 2014. The Organizational Structure of the Public Service and its Role on the Level of Corruption: The Case of Greek Tax Administration. Procedia Social and Behavioral Sciences, 148, pp.494-500. Available at: http://www.sciencedirect.com/science/ article/pii/S1877042814039755.

Alexandria Brysland Adrienne Curry, (2001),"Service improvements in publicservices using SERVQUAL", Managing ServiceQuality: An International Journal, Vol. II lss 6 pp. 389 - 401. Permanent link to this document:http://dx.doi.org/10.1108/09 604520110410601

Bhattacharya, S., Saha, S. \& Banerjee, S., 2016. Income inequality and the quality of public services: A developing country perspective. Journal of Development Economics, 123, pp.1-17. Available at: http://dx.doi.org/10.1016/j.jdeveco.2016. 07.003 .

Bolong, Liu. 2003. Improving the quality of public policy-making in China : Problems and prospect. Public Administration Quarterly, Summer, pp 5-10.

Bourgeonis, Isabele, 2008, Informing evaluation capacity Building Through Profiling Organization, Capacity For Evaluation : An Emprical Examination of Four Canadian Federal Government Organition, The Canadian Journal of Program Evaluation Vol. 23 No. 3, 2008 Pages 127-146 ISSN 0834-1516

Ciobanu, A. \& Androniceanu, A., 2015. Civil Servants Motivation and Work Performance in Romanian Public Institutions. Procedia Economics and Finance, 30(15), pp.164-174. Available at:

http://www.sciencedirect.com/science/ article/pii/S2212567115012800.

Duhamel, F. et al., 2014. IT outsourcing in the public sector: a conceptual model. Transforming Government: People, Process and Policy, 8(1), pp.8-27. Available at: http://dx.doi.org/10.1108/TG-05-20130012.

Darmi, Titi (2013), Penerapan Budaya Organisasi, Kinerja Organisasi dan 
Kinerja Aparatur.jurnal Ilmiah]AP UNR, .Vol.2 No 113 November: 7-11

Denhardt, J.V., \& Denhardt, R.B. 2003. The new public service: Serving, not streering. Among NY. ME. Sharpe.

Deininger, K., \& Mpuga. 2005. Does Greater Accountability Improve the Quality of Public Service Delivery? Evidence from Uganda. , 33(1), pp.171-191.

Dwiyanto, A (2013), Reformasi Birokrasi Publik di Indonesia, Cetakan Pertama, Yogyakarta: Galang Pritika.

Edwards III, G. C. 1980. Implementing Public Policy.Washington, D.C. Congressional Quarterly Press.

Elston, T., 2016. Conflict between Explicit and Tacit Public Service Bargains in U.K. Executive Agencies. Governance, 30(1), p.n/a-n/a. Available at: http://dx.doi.org/10.1111/gove.12191/nhtt p://onlinelibrary.wiley.com/store/10.1111 /gove.12191/asset/govel2191.pdf? v=l\&t=i kh4lqvo\&s=6ccbb468dc0cf07132556a e35cf9ef9aealldif2.

Grindle, Merilee, S. 1990. Politics and politics implementation in the Third Generation, Scott, Foresman and Company, llinois.

Grindle, Merilee, S., \& Thomas, J.W. 1991. Public choices and policy change : The policical economy of reform in developing countries. Baltimore : The John Hopkins University Press.

Howlett, Mechael andRamesh, M. 1995. Studiying public policy:Policy cycles and policy subsystems. Toronto, Oxford University Press.

Howlett, Mechael., Ramesh, M., and Pearl, A. 2003. Studiying public policy: Policy cycles and policy subsystems. Don Mills, ON, Oxford University Press.

Juliani, F. \& Oliveira, O.J. De, 2016. International Journal of Information Management State of research on public service management: ldentifying scientific gaps from a bibliometric study. , 36, pp.10331041.

Jones dan George (2005). Understanding and Managing Organizational behaviour 4th edition. Pearson. Prentice Hall.

Johannes, B. 2006. Budaya organisasi: Konsep dan terapan. Yayasan Pembinaan. Jakarta

Kamuli, Sukarman (2014), Evaluasi Tentang Implementasi Kebijakan Pengembangan Kawasan Minipolitan di Kabupaten Gorontalo Utara, Jurnal Mimbar LPPM UNISBA, Vol 30 no 1 Juni: 53-61.

Keban, Y. T. 2008. Enam deminsi strategi adminidtrasi publik: Konsep, teori, dan isu), eds 2, Gava Media. Yogyakarta.

Kusnandar, 1. 2005. Pengaruh Implementasi Kebijakan terhadap Kualitas Pelayanan lzin Mendirikan Bangunan.Disertasi. Bandung PPs UNPAD. 
Mahalingam, Ravi. 2012. Dynamics of Public Policy-making in Malyasia ; The Formulation of Nasional Biotechnology Policy. Administrasi and Public Management, 19, pp. 5164.

Maarse, F (1994), Implementation Of Public Policies, Swets Noth Amereka: Berwyn.

Nugroho, Riant. 2014. Kebijakan publik di negara - negara berkembang, Yogyakarta, Pustaka Pelajar.

Person, W. 1997. Public policy: An introduction to the theory and practice of policy analysis. Cheltenham. Edwar Elgar.

Purwanto, E. A., \&Sulistyastuti, D. R. 2012. Implementasi Kebijakan Publik: Konsep dan Aplikasinya di Indonesia. Gava Media: Yogyakarta

Robbins, S.P., \& Judge, T, A. 2015. Perilaku Organisasi, eds 16. Senior editor Aklia suslia. ISBN 978979061515 1, penerbit Salemba empat, Jakarta.

Santoso, M.1., 2015. Applying Interactive Planning on Public Service Leadership in The Directorate General of lmmigration Indonesia. ScienceDirect. Procedia - Social and Behavioral Sciences, 169(August 2014), pp.400-410. Available at: www.sciencedirect.com.

Sampara, L. 1999. Manajemen Kualitas Pelayanan,STIA Lembaga

Administrasi Negara (LAN), LAN

Press, Jakarta.
Sembiring, M. 2012. Budaya dan Kinerja Organisasi (Persepktif organsiasi pemerintah). Fokusmedia, Bandung.

Starling, G. 1979. The politics and economics of public policy : An instroductory analisysis. Stone, Deborah,A. 1989. Causal stories and the formations of policy agenda. Political Science Quarterly, 104 ( 2), pp. $281-300$.

Suwitri, Sri. 2011. Jejaring kebijakan dalam perumusan kebijakan publik, Semarang. Badan Penerbit Universitas Diponegoro.

Suwitri, Sri., Purnaweni, Hartuti., dan Kismartini. 2014. Analisis kebijakan publik. Jakarta. Penerbit Universitas Terbuka.

Targerson, Douglas. 2007. Promoting the policy orientation ; Lasswell in Contect. In : Frank Fischer, Gerald J Miller, and Mara S Sedney. Eds, handbook of policy analysis: Theory, polotics, and methods. B Roton. CRC Press, Taylor and Francis Grouf, pp. $15-28$.

Tjiptono, fandy. 1996. Manajemen Jasa, Andi. Yogyakarta.

Zeithaml, V, A., Parasuraman, A., Leonard, L. B. 1990. Delivering quality service. New York. The Free Press 